\title{
Sezary syndrome: diagnosis and management
}

\author{
${ }^{1} \mathrm{C}$ Ogilvie, ${ }^{2} \mathrm{R}$ Jackson, ${ }^{3} \mathrm{M}$ Leach, ${ }^{4} \mathrm{P}$ McKay \\ ${ }^{1}$ Specialty Trainee, Department of Haematology, Beatson West of Scotland Cancer Centre, Glasgow; ${ }^{2}$ Consultant Pathologist, Department of \\ Pathology, Glasgow Royal Infirmary, Glasgow; ${ }^{3,4}$ Consultant Haematologist, Department of Haematology, Beatson West of Scotland Cancer \\ Centre, Glasgow, UK
}

\begin{abstract}
We describe a case of a delayed diagnosis of Sezary syndrome in a patient with longstanding generalised pruritus, erythroderma, alopecia and nail dystrophy. We highlight some of the difficulties in diagnosis despite the fact that all patients have a characteristic circulating malignant T-cell lymphocyte in peripheral blood. These cells with cerebriform nuclei should be sought in peripheral blood films and further evaluated using flow cytometry in all patients with an erythrodermatous presentation. We summarise current treatment options although, as with all rare diseases, there are few randomised controlled clinical trials to inform decisions on optimal therapy for each individual patient.
\end{abstract}

Correspondence to C Ogilvie Beatson West of Scotland Cancer Centre, 1053 Great Western Road, Glasgow GI2 OYN, UK

tel. $+44(0) 1413017738$

e-mail

catherine.ogilvie@ggc.scot.nhs.uk

KEYWORDS Sezary syndrome, Sezary cells, erythroderma, flow cytometry

DECLARATION OF INTERESTS No conflicts of interest declared.

\section{INTRODUCTION}

Sezary syndrome (SS) is a triad of erythroderma, generalised lymphadenopathy and the presence of clonally related neoplastic T-cells with cerebriform nuclei (Sezary cells) in skin, lymph nodes and peripheral blood. These cells can be easily overlooked in peripheral blood smears: the nuclear folding may only be apparent after careful examination at high power under immersion oil. In addition, one or more of the following criteria are required: an absolute Sezary cell count of at least $\mathrm{I} \times 10^{\circ} / \mathrm{L}$, an expanded CD4 positive T-cell population resulting in a CD4/CD8 ratio greater than ten and/or loss of one or more T-cell antigens.' It accounts for $<5 \%$ of all cases of cutaneous T-cell lymphoma (CTCL). Sezary syndrome typically presents in adults over 60 years of age, with a male predominance. Initially the presentation with generalised itch and erythroderma may be non-specific. In up to one-third of skin biopsies (later confirmed as SS) the histologic picture may be non-specific, making diagnosis difficult and consequently delayed. In more advanced cases there may be alopecia, ectropion, onychodystrophy and palmar/plantar hyperkeratosis. Lymph nodes commonly show dermatopathic changes, however a monotonous infiltrate of Sezary cells with loss of normal architecture is typical of nodal involvement. The bone marrow is often not involved but may show a light, predominantly interstitial, infiltrate.

\section{CASE REPORT}

A 72-year-old female presented to Dermatology with a diffuse itchy erythroderma affecting her face, trunk, legs and palms. This was extensively investigated but no clear cause was identified. The full blood count was normal and a skin biopsy was in keeping with a chronic dermatitic process. The biopsy was reviewed specifically by a lymphoma pathologist and no overt features of $\mathrm{CTCL}$ were present. She was treated with topical steroids and antihistamines.

Over the subsequent two years her symptoms worsened with intense itch, peeling of the skin of her palms and soles, marked dystrophy of her nails (hands and feet) and extensive, patchy alopecia. She did not have type B symptoms of lymphoma.

Examination revealed generalised mild erythroderma with loose, thickened skin, marked peeling of her palms and soles and nail dystrophy. There was patchy alopecia, loss of eyelashes and mild bilateral ectropion (Figure I). A $2 \mathrm{~cm}$ right axillary node and $\mathrm{I} \mathrm{cm}$ left groin node were palpable. She had a peripheral blood lymphocytosis of $8 \times 10^{9} / \mathrm{L}$ with a population of atypical lymphocytes with convoluted nuclei (Figure 2A). Flow cytometry showed an abnormal CD3 positive, CD4 positive T-cell population showing partial loss and weak expression of CD7, but absent CD25, with an absolute count of $3 \times 10^{9} / \mathrm{L}$. Further skin biopsy showed a prominent epidermotropic CD4 positive T-cell infiltrate involving the lower third of the epidermis (Figure 2B). A computed tomography (CT) scan showed bilateral axillary and bilateral inguinal lymphadenopathy only and bone marrow trephine showed no evidence of infiltration. An axillary node biopsy showed florid dermatopathic changes in addition to early involvement with CTCL. The same monoclonal T-cell receptor gene rearrangement was identified by polymerase chain reaction (PCR) in peripheral blood, skin biopsy and lymph node biopsy, confirming a diagnosis of Sezary syndrome (Figure 3). 

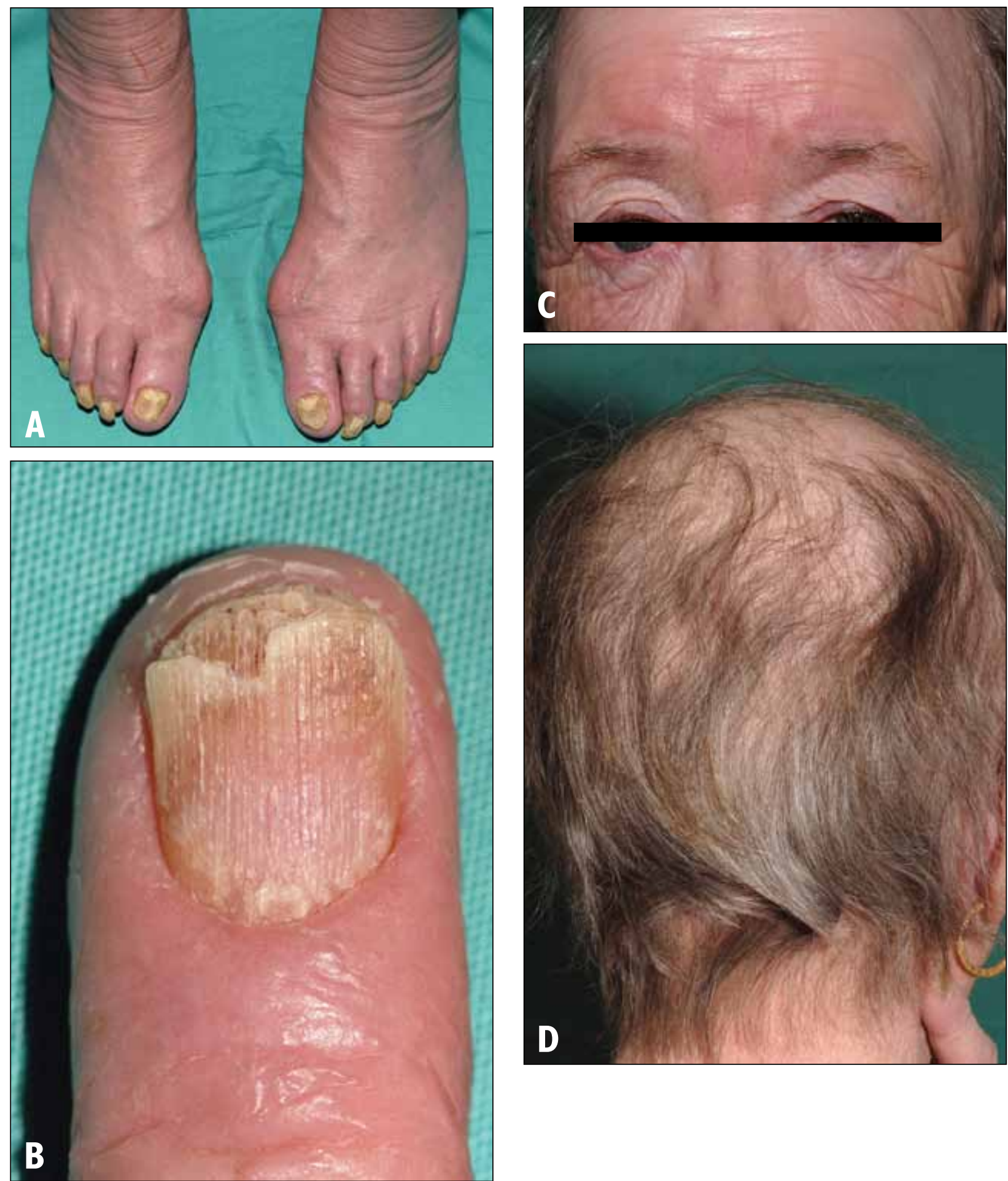

FIGURES IA Loose, thickened skin; B nail dystrophy; C loss of eyelashes and bilateral ectropion; D patchy alopecia.

\section{DISCUSSION}

Sezary syndrome is an aggressive, incurable disorder with a 10-20\% five-year overall survival rate. The European Organisation for Research and Treatment of Cancer (EORTC) have produced guidelines for the management of CTCL. ${ }^{2}$ First-line recommendations for treatment of SS are extracorporeal photopheresis (ECP), interferon alpha +/- psoralen combined with ultraviolet A (PUVA), low-dose chlorambucil with prednisolone and denileukin diftitox (an IL2-diptheroid toxin fusion protein). There are few phase III randomised studies to assist decisions on optimal first-line therapy. Most published evidence comes from small case series and expert opinion. Treatment is aimed at symptom control, with partial Sezary cell clearance being the norm. Complete clinical responses to treatment are unusual. 


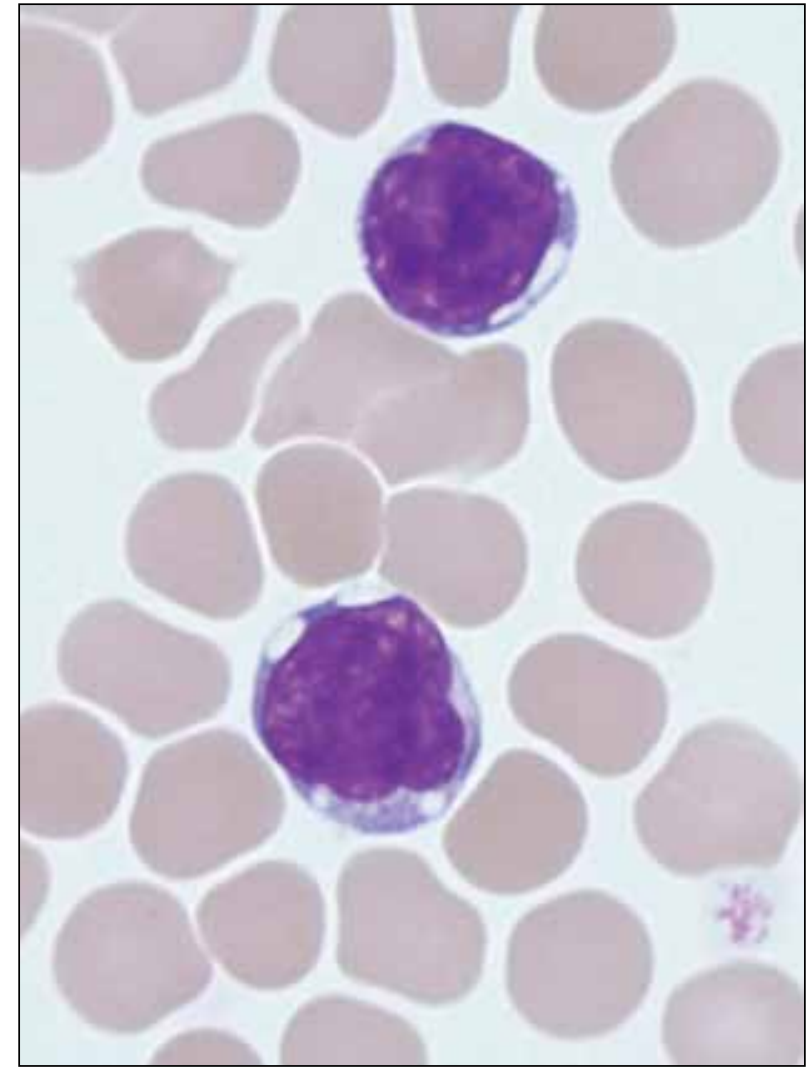

FIGURE 2A Sezary cells in peripheral blood; atypical lymphocytes with convoluted nuclei.

The use of ECP will achieve a response in $55-70 \%$ of patients: responders tend to have a higher baseline lymphocyte count and proportion of Sezary cells. Extracorporeal photopheresis is currently only available through six centres in the UK. A typical regimen might consist of treatment on two consecutive days every two weeks for the first three months and then monthly for the following nine months, according to clinical response. Cells undergo leukapheresis and then photoactivation with 8-methoxypsoralen (8-MOP) in combination with UVA. The 8-MOP binds covalently to DNA in the separated leucocytes resulting in cell cycle arrest and apoptosis. Once re-infused, the apoptotic leucocytes are phagocytosed by antigen-presenting cells. This results in production of specific tumour suppressor cells which go on to target malignant lymphocytes. ${ }^{3}$

Chlorambucil and prednisolone therapy is one of the longer established regimes for this condition. ${ }^{4}$ It has been shown to prolong survival by a median of 3.2 years, from the onset of erythroderma, when compared to a variety of other combination chemotherapy and irradiation regimens. A low dose of chlorambucil, typically $4 \mathrm{mg}$ daily, is given continuously with prednisolone in tapering doses according to response.

Interferon alpha therapy can achieve meaningful responses in up to $64 \%$ of CTCL patients, with time to progression of 4 to 27 months, when used in escalating

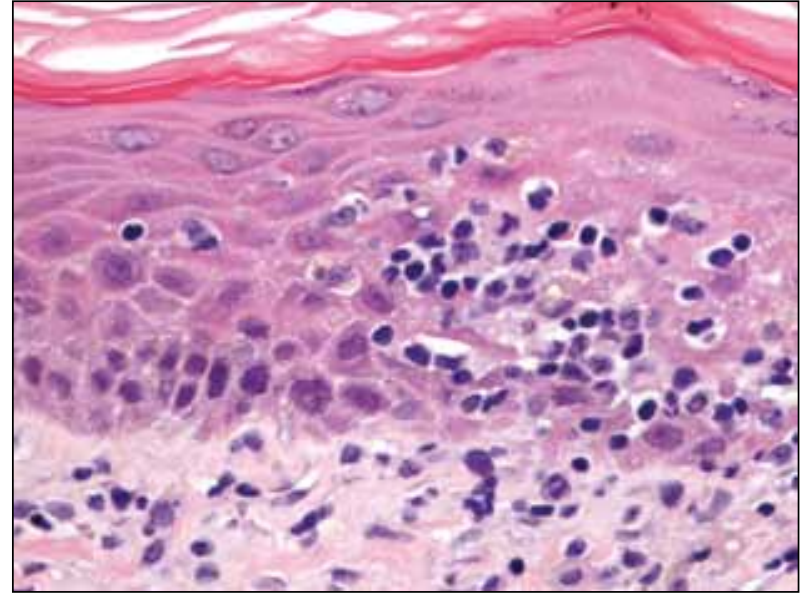

FIGURE 2B CD4 positive T-cell infiltrate involving the lower third of the epidermis (skin biopsy, H\&E stain, $\times 400$ magnification).

doses from $3 \mathrm{MU}$ daily for a maximum of ten weeks. ${ }^{5}$ Dose-related side-effects of malaise, depression, anorexia and weight loss, however, were common. Denileukin diftitox has been studied in CD25 positive CTCL cases with an overall response in $30 \%$ of patients. ${ }^{6}$ The majority of SS cases, however, are CD25 negative. Second-line treatments have been assessed only in very small studies. Methotrexate given weekly at a dose of 5-25 mg has been reported to achieve a response in 13

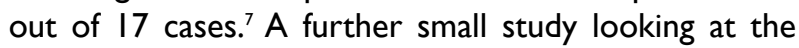
efficacy of bexarotene achieved a response rate of $24 \%{ }^{8}$ Alemtuzumab therapy can achieve initial responses but many cases show early disease progression. ${ }^{9}$ Combination chemotherapy regimens (etoposide, prednisolone, vincristine, cyclophosphamide and daunorubicin [EPOCH], fludarabine/cyclophosphamide, and cyclophosphamide, vincristine, prednisone [CVP]) have been used in refractory CTCL but the experience in treating SS is extremely limited. Despite reported responses of up to $80 \%$, many of these regimes are toxic and immunosuppressive and will not be tolerated by many patients. ${ }^{10-12}$ In well-selected young patients with a suitable sibling donor, reducedintensity conditioning allogeneic transplantation should be considered and an estimated three-year survival of $54 \%$ has been reported. ${ }^{13}$ Importantly, many patients with SS die of opportunistic infection as a result of progressive depletion of normal CD4 positive T-cells through the effects of the disease and its treatment.

We chose to commence therapy with prednisolone $20 \mathrm{mg}$ daily for the first few weeks prior to the introduction of more definitive therapy with ECP. She had an excellent early response with rapid improvement of the pruritus, allowing uninterrupted sleep, with a lessening of the peeling and fissuring of the palms and soles. The patient also showed a good early response to ECP. She has received six photophoresis treatments to date and there has been a significant improvement in the erythroderma. 


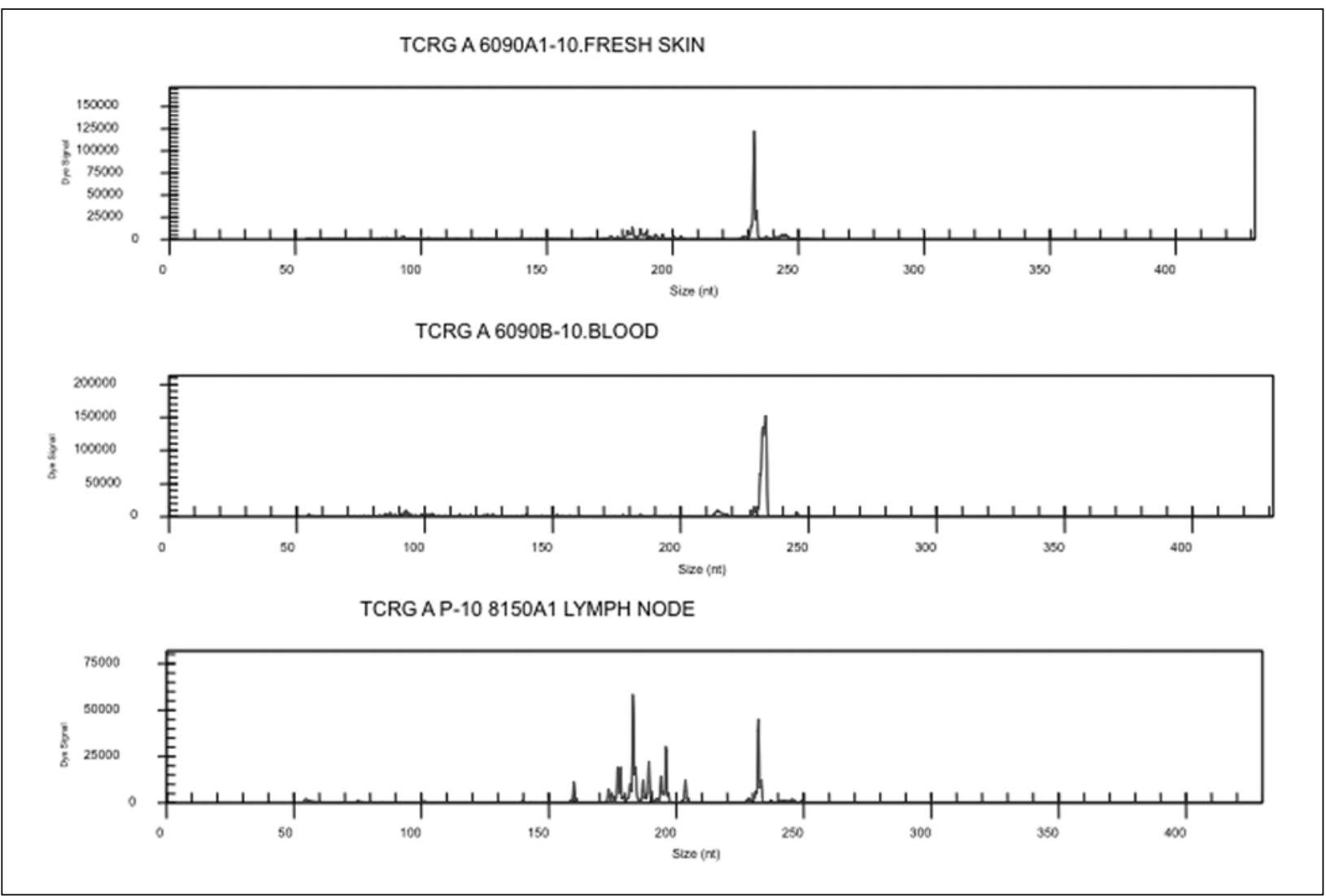

FIGURE 3 The same monoclonal T-cell receptor gene rearrangement was identified by PCR in skin biopsy specimen, peripheral blood and lymph node specimen.

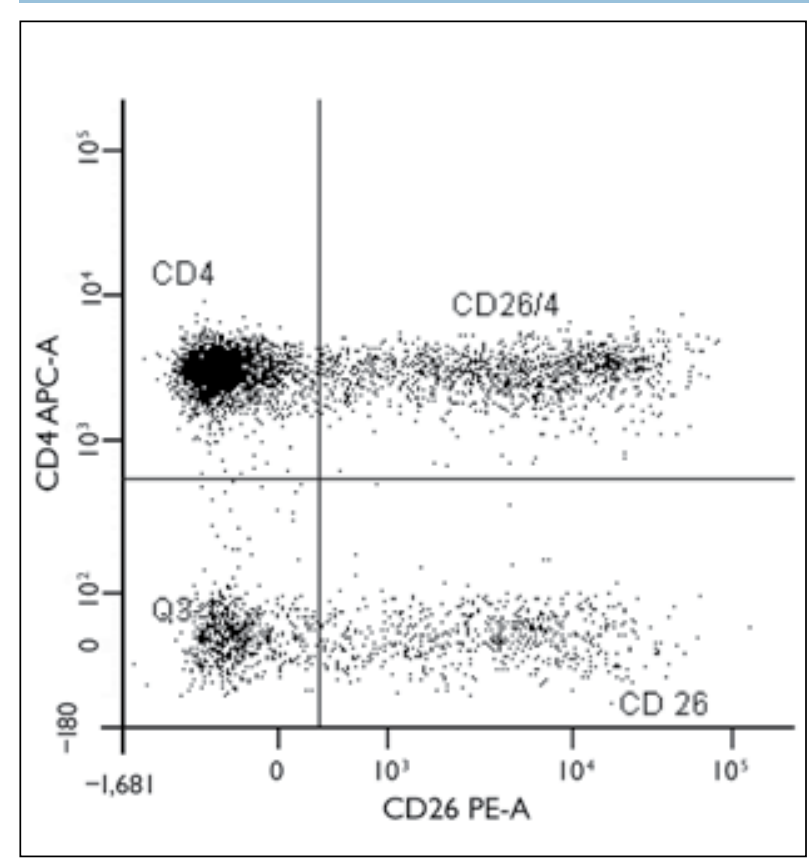

FIGURE 4 Dotplot showing typical phenotype of Sezary cells, CD4+/CD26 weak. Taken from a patient diagnosed with Sezary syndrome following the introduction of CD26 to our immunophenotyping panel.

\section{CONCLUSION}

Sezary syndrome is a rare disease characterised by the triad of erythroderma, generalised lymphadenopathy and the presence of clonally related neoplastic T-cells with cerebriform nuclei (Sezary cells) in skin, lymph nodes and peripheral blood.

All patients presenting with unexplained erythroderma should have a peripheral blood film scrutinised for the typical lymphoid cells with cerebriform nuclei and flow cytometry for the detection of a CD4 positive population lacking one or more T-cell antigens. Typical Sezary cells are CD3 positive, CD4 positive with loss or weak expression of CD7 and CD26. ${ }^{14}$

Sezary syndrome incurs significant morbidity causing intractable pruritus, skin damage, nail dystrophy and alopecia and a poor prognosis, with a median survival of two to four years. Although treatment guidelines exist, there is still uncertainty with respect to the optimal initial therapy for patients. 


\section{REFERENCES}

I Campo E, Swerdlow SH, Harris NL et al. WHO classification of tumours of haematopoietic and lymphoid tissues. [Internet] Geneva: World Health Organization; 2008 [cited 2012 Nov 2I]. Available from: http://apps.who.int/bookorders/anglais/detartl.jsp?codlan= I \& codcol $=70 \& \operatorname{codcch}=4002$

2 Trautinger F, Knobler R, Willemze R et al. EORTC consensus recommendations for the treatment of mycosis fungoides/Sezary syndrome. Eur J Cancer 2006; 42:1014-30. http://dx.doi. org/I0.1016/j.ejca.2006.01.025

3 Scarisbrick JJ, Taylor P, Holtick U et al. UK consensus statement on the use of extracorporeal photopheresis for treatment of cutaneous T-cell lymphoma and chronic graft versus host disease. $\mathrm{Br} J$ Dermatol 2008;I58:659-78.http://dx.doi.org//0.I I I I/j.I365-2I33.2007.084I5.x

4 Winkelmann RK, Diaz-Perez JL, Buechner SA. The treatment of Sezary syndrome. J Am Acad Dermatol 1984; 10:1000-4. http:// dx.doi.org/I0.1016/S0190-9622(84)80323-0

5 Olsen EA, Rosen ST, Vollmer RT et al. Interferon alfa-2a in the treatment of cutaneous T cell lymphoma. J Am Acad Dermatol 1989; 20:395-407. http://dx.doi.org/I0.10I6/S0 I90-9622(89)70049-9

6 Olsen E, Duvic M, Frankel A et al. Pivotal phase III trial of two dose levels of denileukin diftitox for the treatment of cutaneous T-cell lymphoma.J Clin Oncol 200I; 19:376-88.

7 Zackheim HS, Epstein Jr EH. Low-dose methotrexate for the Sezary syndrome. J Am Acad Dermatol 1989; 21:757-62. http:// dx.doi.org/I0.1016/S0190-9622(89)7025I-6

8 Duvic M, Hymes K, Heald P et al. Bexarotene is effective and safe for treatment of refractory advanced-stage cutaneous $T$ cell lymphoma: multinational phase II-III trial results. J Clin Oncol 200I; 19:2456-7|.
9 Kennedy GA, Seymour JF,Wolf $M$ et al. Treatment of patients with advanced mycosis fungoides and Sezary syndrome with alemtuzumab. Eur J Haematol 2003; 7I:250-6. http://dx.doi. org/I0.1034/j.1600-0609.2003.00I43.x

10 Akpek G, Koh HK, Bogen S et al. Chemotherapy with etoposide, vincristine, doxorubicin, bolus cyclophosphamide and oral prednisolone in patients with refractory cutaneous T-cell lymphoma. Cancer 1999; 86:1368-76. http://dx.doi.org//0.1002/(SICl)/097. 0I42(I999I00I)86:7<1368::AID-CNCR37>3.0.CO;2-8

I I Scarisbrick J], Child FJ, Clift A et al. A trial of fludarabine and cyclophosphamide combination chemotherapy in the treatment of advanced refractory primary cutaneous T-cell lymphoma. Br J Dermatol 2001;144:1010-5.http://dx.doi.org/I0.1046/j.I365-2I33.200I.04I9I.x

12 Tirelli U, Carbone A, Zagonel V et al. Staging and treatment with cyclophosphamide, vincristine and prednisolone (CVP) in advanced cutaneous T-cell lymphomas. Hematol Oncol 1986; 4:83-90. http:// dx.doi.org/I0.1002/hon.2900040II0

I3 Duarte RF, Canals C, Onida F et al. Allogeneic hematopoietic cell transplantation for patients with mycosis fungoides and Sezary syndrome: a retrospective analysis of the Lymphoma Working Party of the European Group for Blood and Marrow Transplantation. J Clin Oncol 2010; 28:4492-9. http://dx.doi.org//0.I200/ |CO.2010.29.324|

14 Jones D, Dang NH, Duvic M et al. Absence of CD26 expression is a useful marker for diagnosis of T-cell lymphoma in peripheral blood. Am J Clin Pathol 200 I; I I5:885-92. http://dx.doi.org/ I0.1309/ UIY6-J4AG-5M4M-7AYV 